\title{
Применение современной ИК термографии для изучения скорости пульсовой волны
}

\author{
Б.Г. Вайнер ${ }^{1,2}$ \\ ${ }^{1}$ Институт физики полупроводников им. А.В. Ржанова СО РАН, \\ Новосибирск, 630090, пр-т Ак. Лаврентьева, 13 \\ ${ }^{2}$ Новосибирский государственный университет, Новосибирск, 630090, ул. Пирогова, 2 \\ тел: +7 (383) 330-7781, эл. почта: $\underline{\text { BGV@isp.nsc.ru }}$
}

DOI 10.34077/RCSP2021-34

Скорость распространения пульсовой волны (pulse wave velocity - PWV) в артериях является общепризнанным показателем жесткости сосудов, которая, в свою очередь, характеризует состояние кардиоваскулярной системы и служит предвестником развития грозных заболеваний (гипертония и пр.). Обычно, определяя PWV, усредняют порядка 10-20 измеренных значений ввиду разброса показаний, обусловленного, в частности, влиянием легочного дыхания [1]. Однако, вплоть до настоящего времени не было проведено исследований, позволяющих сопоставить фазу амплитудной модуляции PWV с фазой циркуляции воздуха в дыхательных отверстиях. С учетом того, что возможный фазовый сдвиг здесь способен количественно характеризовать функциональную взаимосвязь дыхательной и сердечно-сосудистой систем организма, получение объективной информации о данном параметре является высоко актуальным.

В проведенных исследованиях применена оригинальная технология, впервые позволившая подойти к решению сформулированной выше проблемы и получить пилотные результаты. Для измерения PWV в лучевой артерии был использован способ, описанный автором доклада в $[2,3]$. Прецизионное измерение динамики дыхания производилось оригинальным методом сорбционно усиленной инфракрасной термографии [4] с применением высокоскоростного (100 кадров в секунду) высокочувствительного $\left(0.03{ }^{\circ} \mathrm{C}\right)$ тепловизора ТКВр-ИФП/СВИТ, разработанного и изготовленного в ИФП CO РАН. Непрерывные измерения PWV и профиля дыхания (по вариации температуры сорбционного индикатора) проводились синхронно, результаты

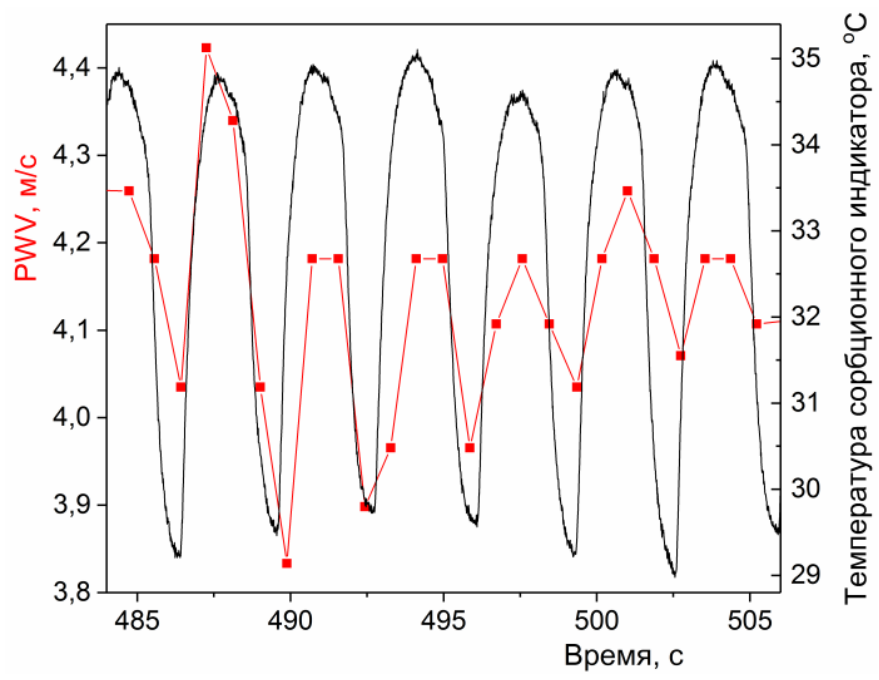

Рис. 1. Совмещение во времени характеристик PWV и дыхания. Последняя измерена тепловизионным методом с применением матричного ИК детектора. Видно, что вдох (охлаждение индикатора) вызывает уменьшение PWV, а выдох - увеличение. передавались в память компьютера. Высокое быстродействие тепловизора было решающим фактором, позволившим сопоставить динамические респираторные и PWV характеристики.

Пример такого сопоставления приведен на рис. 1. Ясно определяется осциллирующее поведение скорости пульсовой волны. При анализе периода осцилляций было высказано предположение, что наблюдаемый эффект - "след" легочного дыхания. Для проверки этой гипотезы временные зависимости PWV и дыхания были совмещены (рис. 1) и при неоднократных измерениях получена высокая степень их корреляции (коэффициент Пирсона $r=+0.67$.. 0.80).

Измерения также были проведены в режиме принудительного (не спонтанного), дыхания с частотой, заданной метрономом. Полученные результаты подтверждают, что тепловизионная фотоника является уникальным инструментом биофизических и биомедицинских исследований. Представленная в докладе методика вполне может быть применена и к исследованию животных.

\section{Лumepamypa}

[1] H. Edgell, M.K. Stickland, J.E. MacLean // Blood Press. Monit. 2016. Vol. 21. P. 192-195.

[2] B.G. Vainer // In: Bioinformatics of Genome Regulation and StructurelSystems Biology (BGRSISB2018). Novosibirsk: ICG SB RAS, 2018. P. 146. DOI: 10.18699/BGRSSB-2018-118

[3] B.G.Vainer // In: Measurement 2019. Proc. 12th Int. Conf., May 27-29, 2019, Smolenice, Slovakia. Bratislava: Institute of Measurement Science Slovak Academy of Sciences. P. 115-118. ISBN 978-80972629-2-1.

[4] B.G. Vainer // Ann. Biomed. Eng. 2018. Vol. 46. P. 960-971. 